\title{
ETHICS IN THE CONSERVATION AND RESTORATION OF EARLY BRASS INSTRUMENTS
}

\section{Robert Barclay}

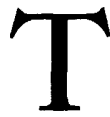

he intention of this paper is to discuss some aspects of the preservation of brass instruments in museum collections and to contrast these with the restoration needs of working instruments. From experiences over the last few decades it has become clear that the opening statement of Preservation and Restoration of Musical Instruments, that "Where possible the restoration of a deteriorated instrument is commendable" (see Recommended Reading), can no longer be supported in a museum context. Discussions on musical instrument care have centered on the problems of restoration vs. conservation and it has become evident that restoration of instruments in the public domain has, in many cases, resulted in irreversible damage to unique examples and significant loss of historical evidence. The same is true in the private sector and, although a clear distinction exists between the practices of private owners and restorers of musical instruments and those expected of personnel working in and for museum collections, the compromises to the integrity of the instruments in both domains remain an unfortunate constant. Before proceeding much further it would be wise to define what we understand the terms "conservation" and "restoration" to mean.
In almost all non-English speaking countries the term "conservation" applies to the domain of the curator, while the staff member who treats objects, regardless of the ethical and technical status of the work, is engaged in restoration. To the contrary, in the Englishspeaking world, conservation as a descriptor originated as a result of purely preventive treatment applied to archaeological objects. It attempted to distinguish between the technical preservation of fragile and unstable artifacts and what was then perceived to be the less thoughtful and more wholesale beautification of museum pieces for display. Even though the bona fide discipline of conservation came into being half a century ago, and came to embrace the treatment of all museum objects, it is still not well understood. I know a curator who still persists in calling people in my profession "conservationists" (perhaps a step up from restorers) and I have yet to find a journalist who though conservation was not concerned with acid rain and endangered species. Speak of restoration and they all know where you stand. The International Council of Museums (ICOM), when given an opportunity to clarify once and for all the distinction, opted for the portmanteau term conservator/restorer, which advances

Robert Barclay has been conservator of musical instruments at the Canadian Conservation Institute in Ottawa since 1975. He is also a maker of natural trumpet reproductions. 
public understanding hardly at all.

The Code of Ethics for Conservation defines conservation as:

All actions aimed at the safeguarding of cultural property for the future. The purpose of conservation is to study, record, retain and restore the culturally significant qualities of the object with the least possible intervention.

With this definition in mind it is apparent that the chief aim of conservation treatment is stabilization in a present state. If an instrument is unplayable, conservation treatment will not make it otherwise. In the specific case of brass instruments, the "least possible intervention" might preclude such treatments as polishing, soldering, straightening and dent removal. It could be argued on ethical grounds that all the above operations might remove or compromise information of cultural value. Restoration, on the other hand, is defined in the same document as:

All actions taken to modify the existing materials and structure of a cultural property to represent a known earlier state. The aim of restoration is to preserve and reveal the aesthetic and historical value of a cultural property. Restoration is based on respect for the remaining original material and clear evidence of an earlier state.

The key concept here is the modification of the object to represent an earlier, usually original, state. Between conservation and restoration a hierarchy of treatment is often perceived, from pure conservation at one end to radical and irreversible restoration at the other. This, however, is a faulty perception; it is far more realistic to regard conservation as a sub-set of restoration. Thus, restoration can include conservation, but conserva- tion cannot include restoration. To the conservator, the least interventive treatment is the most desirable, although it is farito say tt this point that pure conservation, even as practiced $i$ the most ethical of museum laboratories, is a rare thing. some small element of restoration, of marginal improvement in appearance, is almost always implicit in even the most simple conservation treatment.

On the surface, restoration has always appeared a desirable end; this is certainly the central thesis of the publication cited in the first paragraph. Metal is such a tractable material that repairs and alterations are more likely than not to be found on early instruments. But what are the reasons for performing a treatment that may alter the given state of a musical instrument? In the museum, treatment is done for three basic reasons: for preservation, for display and for performance. Using as a guide the degree of intervention, let us examine these three:

Preservation can be accomplished by the most minimal intervention and requires no major chemical, physical or structural changes to the instrument (unless in cases of severe active corrosion.). Correct storage, conducive environment and careful handling may be all that are required to accomplish preservation. This is conservation in essence.

Display is perceived by both museum staff and the viewer to require the attractive appearance of the instrument. To achieve this it may be considered necessary to remove dents, patch weak areas, polish the exterior, attach missing pieces and, most important of all, remove previous improper repairs or faulty restorations. Preparation for display can therefore be more interventive than treatment solely for preservation. While it can 
be a purely conservation task, it is more likely to involve an element of restoration.

Performance generally involves the greatest intervention during treatment of a brass instrument. Not only must it be attractive in appearance, it must also function perfectly acoustically and mechanically. The intervention necessary to accomplish this often alters profoundly the characteristics of the instrument and the material from which it is composed. It is rare for an instrument to be returned to playability while still adhering to the tenets of conservation practice.

Why does treatment beyond simple conservation affect brass instruments, and in what way? Some of the more extreme processes applied to brass instruments cause irreversible changes to the metal. These specifically are reshaping, soldering and polishing. Following are some of the factors to be taken into account:

Reshaping. Brass consists of a solid solution of zinc in copper. In modern brasses, the proportion of zinc is in the order of 30 percent; brasses from the 18 th century and earlier contain considerably less, and may include other metallic impurities. When examined under the microscope, brass shows a characteristic granular nature in which crystal-like growth during cooling has created discrete zones. Because of this granular nature, brass is capable of being annealed and tempered by heating and working respectively. Heating followed by rapid cooling causes formation of small, randomly oriented granules giving a soft, easily worked material. Working by hammering, burnishing or spinning causes orientation of the granules, thus "locking" them into a less tractable state. Old brasses, and any brass that has been worked, tend to be hard to the point of brittleness and may fracture along grain boundaries if stressed. In addition, tiny electrolytic cells may be set up within the brass, usually at the boundaries and around inclusions of impurities. An electrical potential between the copper and zinc, in the presence of water, oxygen and other impurities, causes an exchange of electrons resulting in intergranular corrosion, which weakens the brass and makes it especially susceptible to stress damage. Any attempt to reshape brass, such as dent removal or straightening, without prior heat treatment will result in distortion and damage, especially if corrosion-related microfissures already exist. Because brass must be heat-treated before working, any specific orientation in the material due to original manufacturing techniques will be obliterated. For the student of brass working techniques, this is far from desirable.

Soldering. Hard soldering, in which the brass must be heated to a temperature close to red heat, will obliterate granule orientation. Also, when brass and other copper-based alloys have been allowed to patinate naturally over a period of many years, an even, stable oxide known as a passivating layer is formed. This has the effect of inhibiting further corrosion. In brass, this passivating layer can be very attractive; in silver (for example) it is the familiar ugly brown/blue/black tarnish. Any patination the instrument may have will be removed by heating during hard soldering, thus necessitating repolishing. Low temperature soldering, using alloys of such metals as lead, tin and bismuth, can be an alternative; it will not destroy granular features 
and patination may also be preserved. However, effective soldering requires intimate contact between the metals being joined and such a joing is never removable, should the need arise, without loss of original material.

Polishing. Polishing is generally an abrasive process. No matter how carefully it is done and with what kind of polish, material is always removed. Because the surface of any metal is never truly smooth microscopically, much metal must be removed from high spots before all corrosion is removed from low-lying areas. Repeated polishing on old metal artifacts is evidenced by blurring of engraving, loss of tool marks and even substantial thinning. A newly polished surface is highly reactive to oxidation. Under certain conditions a passivating layer may be reestablished after polishing, but the presence of finger marks, atmospheric impurities and other pollutants can cause this to form very unevenly. Because we are generally unable to control rigorously the environment surrounding our instruments, the decision to polish carries with it the obligation to repolish. Polishing a metal instrument for display or for use in performance may begin a pernicious cycle.

Clearly, reshaping, soldering and polishing, three of the chief techniques available to the brass instrument restor$\mathrm{er}$, are detrimental to the physical integrity of the object to which they are applied. It is therefore difficult, if not impossible, to perform a full restoration without compromise; without, in fact, contravening the museum-based Code of Ethics for Conservation. Indeed, the framework of this discussion has so far been within museum collections. How well do such exacting standards apply outside the museum world? some of the more conservative conservators would like to see these same exacting standards applied to instruments in private hands, the argument being that they, too, are objects of cultural value and should be protected. My feeling is that it would be a very thin and insipid world if we hardly dared to touch our cultural property for fear of doing it some harm. To the contrary, a sensitive restoration, carefully performed with appropriate materials, can give a well cared-for instrument a new lease on life. The instrument was made to be played, and that is the bottom line. I argue that museum standards must necessarily be at the highest ethical level because the museum exists to safeguard material for future study and understanding. Unless a distinct scholarly aim can be established for a museum restoration, it is better left undone. (The exact definition of the "scholarly aim" lies in the future.) Even in the private sector, where restoration to playability is condoned-is, in fact, a vital part of a thriving early music consciousness-I would plead for foresight and sensitivity. I would plead, ultimately, for good taste, the innate guiding principle of every good restorer.

If we plan to restore a brass instrument, or have it restored by another, we must stand back and ask ourselves, what is the goal? What do we hope to achieve as a result of restoration and at the end will we get what we think we want? Once we step back and examine our motives, we often find that the goal is nowhere near as clear as we first perceived. Here are a few examples of what I see as lack of sensitivity or incomplete reasoning:

I spoke to a museum colleague some time ago about the use of certain brass instruments for performance, and he said that this was impossible because he didn't have time to polish them all. I 
have been to several concerts where tarnished instruments have been played and, on shutting my eyes, I have not found it possible to hear the tarnish. Was the polishing of these instruments for performance necessary, or was it merely a perceived need based on faulty reasoning?

- Is it "tasteful" to polish for the delight of the eye, but at the detriment of the instrument? I have seen beautiful silver Baroque trumpets polished to death on a buffing wheel and displayed in a place where they were guaranteed to begin retarnishing forthwith.

$\checkmark$ I have also seen a seam in a brass bell repaired with gold solder, which was guaranteed not to tarnish when the rest of the instrument did!

- Anybody who has examined an early trombone will know that, to a player brought up on modern instruments, the slides are quite intolerable. If we, therefore, remove the slides and replace them with modern ones (which has been done) to give a freer and easier motion, are we any nearer to understanding the older instrument?

- If we bore holes in a natural trumpet to bring the out-of-tune harmonics into line, what are we learning of early technique? If this is done on a modern reproduction it may be merely expedient; if it is done to a perfectly good 19 th century (or earlier) instrument it is butchery.

More subtle and less obvious are the acoustic considerations accompanying restoration to a presupposed original condition. We know of the aging properties of brass. Players attest that there is a difference between the resonance of an old instrument and that of a faithful modern copy (all else being equal?). But did the old instrument resonate the way it does now when it left the maker's workshop? Does the natural aging of brass, the growth of intergranular microfissures, affect the acoustics in a perceptible way? It is also suspected that machine-made tubing responds very differently than hand-made material. What acoustic effects will result from reworking old material and adding new pieces? In the end, we cannot know if our painstakingly restored original instrument is doing quite what its maker intended. We can approach an understanding, but it will always elude us in the end. This fact alone should caution us to do little rather than much.

Returning briefly to museum philosophy, it is obviously very easy to paint oneself into a corner by restricting treatment to the interventive minimum. There are, of course, sound and persuasive arguments for allowing instruments in a public collection to be plaed, if not in concert, at least for the above (admittedly) vaguely defined purposes of scholarship. To deny this facility would be to cut at the very raison d'etre for assembling a study collection. However, a great deal of thought must go into those instruments that are required to be playable for scholarly research, but are not yet in working condition. The above few examples I have given, drawn mostly from experiences in museums, are sufficient indication that the thought process is not always followed. Each instrument requires a unique treatment protocol where the degree of intervention must be weighed against such factors as the historical value and cultural significance. To give a grossly obvious example, a replaceable 19 th century band instrument will qualify for interventive treatment before a unique item from the 17 th century. The Code of Ethics does not dictate the course of action; it simply guides. The discretion of the custodians of the artifacts comes strongly into play. Is this 
situation really very different in the world outside the museum?

I have argued here for discretion and good taste in restoration, but the assumption has been that restoration will continue at the present pace. I hope this will not be so. I hope that in the future, more reliance will be placed on the use of reproductions, rathern than originals. I would like to see the elevated status of playing upon an original instrument abolished by heightened public awareness. I would like to see the day when playing upon an original instrument is looked upon as not quite de rigueur.

It can be convincingly argued that a faithful copy of an early brass instrument can perform more "authentically" than an original restored to what approximates a primary state. The oftheard criticism that reproductions never come close enough for scholarly purposes is not a good reason for abandoning the concept. It remains to be seen how close it is possible to come, or even necessary to come, in order to satisfy academic requirements. In the case of early brass instruments, the thickness of the metal, the alloy, the dimensions and particularly the working technique are all critical and would need to show a very high order of authenticity. In the private sector, the systematic making of reproductions, as opposed to restoration, is not by any means a difficult course to take-already several trumpetsmiths are producing excellent instruments-but the necessity to do so economically, and to satisfy customers' demands, often incurs compromise. In many cases, the maker cannot satisfy the practical requirements of musicians while still fulfilling the needs of authenticity. The widely available "Baroque" trumpets with fingerholes attest to this. The expectations of musicians must be modified and this will not be possible without a deeper commitment on their part. Slow slides, sharp-rimmed mouthpieces, narrow bores and, of course, the natural harmonic series all dangle temptations to compromise. Early brasses lag well behind keyboards, strings and woodwinds in terms of authenticity, and until players can be weaned away from such devices as machine-made slides and handy fingerholes, the truly authentic reproduction of an early brass instrument will be, like its museum counterpart, simply an unplayable curiosity.

\section{Recommended Reading}

1. Berner, A., van der Meer, J.H. and Thibault, G., Preservation and Restoration of Musical Instruments, ICOM, London, 1967.

2. Anon, ICOM Statutes/Code of Professional Ethics, ICOM, 1987.

3. Anon., Code of Ethics and Guidance for Practice, IIC-CG and CAPAC, 1986.

4. Various authors, Recommendations for Regulating the Access to Musical Instruments in Public Collections, CIMCIM/ICOM, 1983.

5. Karp, C., "Restoration, Conservation, Repair and Maintenance," in Early Music, Vol. 7, No. 1, Jan. 1979 , pp. 79-84.

6. Hellwig, F., "Conservation and Restoration," in Making Musical Instruments, Ford, C. (ed.), Faber and Faber, London, 1979.

7. Barclay, R., The Care of Musical Instruments in Canadian Collections, Technical Bulletin No. 4, rev. ed., Canadian Conservation Institute, 1982.

8. Hellwig, F., "Der Praxis der Restaurierung," in Per Una Carta Europea del Restauro, Olschki, L.S. (ed.), Societa Italiana di Musicologia, Florence, 1987, pp. 305-311. 
9. Karp, C., "Technological Research and the Conservation of Musical Instruments," in Per Una Carta Europea del Restauro, Olschki, L.S. (ed.), Società Italiana di Musicologia, Florence, 1987, pp. 293-289.

10. Barclay, R. (ed.), Anatomy of an Exhibition: The Look of Music, International Institute for Conservation-Canadian Group, Ottawa, 1983.

\section{NEW YORK CORNET ¿ SACBUT ENSEMBLE}

"A royal sound, the aural equivalent of a bright banner, unbelievably beautiful"-CHRISTIAN SCIENCE MONITOR

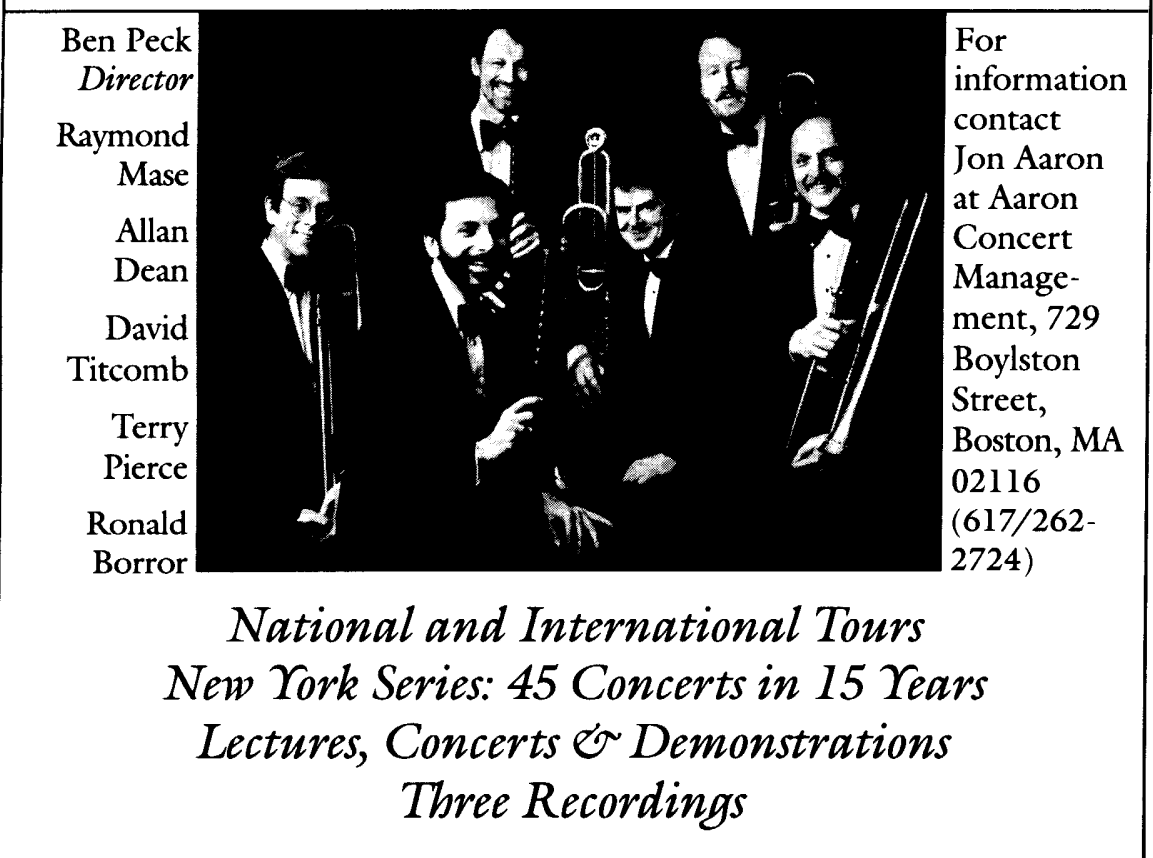

@ FIFTEENTH ANNIVERSARY SEASON @ 